\title{
The use of biogenic ferrihydrite nanoparticles in the reproduction of Ribes nigrum L. lignified cuttings
}

\author{
Natalia Mistratova $^{1 *}$, Valentina Bopp $^{1}$, and Yuri Gurevich ${ }^{2}$ \\ ${ }^{1}$ Krasnoyarsk state Agrarian University, 660049 Krasnoyarsk, Russia \\ ${ }^{2}$ Krasnoyarsk scientific center of the Siberian branch of the RAS, 660036, Krasnoyarsk, Russia
}

\begin{abstract}
The paper presents the results of the use of black currant (Ribes nigrum L.) variety Sofya with lignified cuttings of solutions of nanoparticles of biogenic ferrihydrite in two modifications. Colloidal nanoparticles of "pure" ferrihydrite (Feh) and ferrihydrite doped with aluminum (Feh_Al) have been tested. The research results showed that soaking the cuttings in solutions of nanoparticles and exogenous treatment with these solutions can increase the rooting rate of cuttings of black currant. The maximum rhizogenic activity of cuttings was noted in the variant with ferrihydrite doped with aluminum - 61.9\%, which was statistically confirmed. In the variant with Feh, rooting was lower in comparison with the control by $28.1 \%$ and with the variant Feh_Al by $4.9 \%$ and amounted to $57 \%$.
\end{abstract}

\section{Introduction}

In the Siberian Federal District, own production provides only $15.6 \%$ of the recommended level of consumption of fruit and berry products per person per year. An increase in the production of fruits and berries should be realized through an increase in the area of fruitbearing plantings, variety change and variety renewal based on the intensification of seedling production. Among the berry crops of Siberia, the black currant is the most significant $[1 ; 2]$.

The main breeding method for black currants is cuttings [3]. This method has a high reproduction rate compared to other vegetative methods. However, when propagating by lignified cuttings, there are some disadvantages, for example, the low regeneration capacity of hard-rooted black currant varieties [4]. It is possible to increase the efficiency of black currant propagation by lignified cuttings through the use of nanoparticle solutions.

In modern agriculture, solutions of nanoparticles with great potential are gaining more and more popularity [5]. Due to their unique physicochemical properties, nanoparticles are promising for improving the quality of food, plant protection, detecting diseases, monitoring plant growth, reducing waste, etc. [6; 7]. Nanoparticles contribute to the rapid assimilation of microelements in plants without causing negative effects on the

\footnotetext{
*Corresponding author: mistratova@ mail.ru
} 
environment [8]. Biogenic ferrihydrites appear to be a promising regulator of the activity of the antioxidant system of plant cells, including under conditions of edaphic stresses [9].

The aim of the investigation was to study the effect of solutions of biogenic ferrihydrite nanoparticles on the survival rate of lignified cuttings of black currant (Ribes nigrum L.).

\section{Materials and methods}

The research was carried out in 2019-2020 at the phyto-site of the Department of Plant Production, Selection and Seed Production of the Krasnoyarsk State Agrarian University. The objects of research are black currant (Ribes nigrum L.) variety Sofya and biogenic ferrihydrite nanoparticles. Experimental options: 1) control - water treatment; 2) ferrihydrite (Feh); 3) ferrihydrite doped with aluminum (Feh_Al).

Before planting, lignified cuttings were soaked in nanoparticle solutions $(1 \mathrm{mg} / \mathrm{L})$. Exposition of processing cuttings material 12 hours. The cuttings were planted in open ground at the phyto-site of the department on October 10, 2019, the planting scheme was 30 $\times 30 \mathrm{~cm}$. The experiment was repeated three times, the placement was systematic. During the growing season of 2020, foliar treatment with solutions of nanoparticles was carried out using an aerosol sprayer once every 2 weeks (6 times from June 17 to August 26). Treatment with solutions was carried out in the early morning hours. The rooting of cuttings was counted in the second decade of June. Cuttings were carried out according to the generally accepted technique of MT Tarasenko [10]. Mathematical processing of the research results was carried out by the method of analysis of variance using the MS Exsel computer program.

\section{Results and discussion}

The Taking into account the survival rate of lignified currant cuttings showed that rooting of cuttings depends on the used solution of nanoparticles (figure).

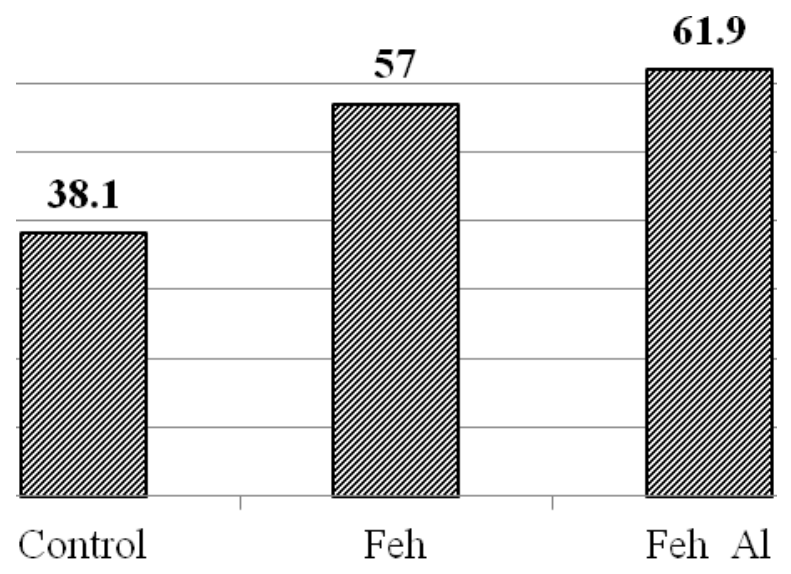

Fig. 1 - Influence of nanoparticle solutions on rhizogenesis of black currant cuttings, $\%,\left(\mathrm{HCP}_{05}=\right.$ 19.6), June 2020

The maximum rhizogenic activity of cuttings was noted in the variant with ferrihydrite doped with aluminum, it was $61.9 \%$, which was statistically confirmed (HCP05 = 19.6). In the variant with Feh, rooting was lower in comparison with the control by $28.1 \%$ and with the variant Feh_Al by $4.9 \%$ and amounted to $57 \%$. A decrease in root formation is 
associated with less favorable hydrothermal conditions at the beginning of the growing season - an increase in temperature in May (plus $4.8^{\circ} \mathrm{C}$ ) and an excess of precipitation $(44.7 \mathrm{~mm})$, there was an excess of moisture in the root layer, high water availability led to a decrease in the regenerative capacity of the cuttings. material for all variants of the experiment. In June, there was $114.5 \mathrm{~mm}$ of precipitation, in July - $157.7 \mathrm{~mm}$, but they were unevenly distributed, dry periods alternated with torrential rains.

\section{Conclusion}

The research results showed that soaking the cuttings in solutions of nanoparticles and exogenous treatment with these solutions can increase the rooting rate of cuttings of black currant, the best rhizogenesis was noted in the variant with Feh_Al - 61.9\%.

\section{References}

1. V. L. Kolesnikova, E. M. Kuzmina, Siberian gardening (Krasnoyarsk, KrasSAU, 2006)

2. V. L. Bopp., E. M. Kuzmina, N.A. Mistratova, Fruit-growing of Siberia (Krasnoyarsk, KrasSAU, 2020)

3. N. A. Mistratova, Improvement of the method of green cuttings for propagation of black currant and sea buckthorn in the conditions of the Krasnoyarsk forest-steppe (Krasnoyarsk, KrasSAU, 2016)

4. N. A Mistratova, Yu. L. Gurevich, M. I. Teremova, A. A. Kolesnik, Bul. of the Kras. St. Agr. Univ., 11 (2019)

5. N. A Mistratova, Rhizogenesis and morphometric changes in blackcurrant cuttings under the influence of biogenic ferrihydrite nanoparticles, Science and education: experience, problems, development prospects (Krasnoyarsk, KrasSAU, 2019)

6. S. A. Suchkova, T. P. Astafurova, Morphological changes in black currant cuttings under the influence of zinc oxide nanoparticles (Tomsk, FGAOU VO NITGU, 2017)

7. V. L. Bopp, N. A. Mistratova, E. A. Petrakovskaya, Y. L. Gurevich, M. I. Teremova, R. G. Khlebopros, Biophysics, 63(4) (2018)

8. V. L. Bopp, N. A. Mistratova, E. A. Petracovskaya, M. I. Teremova, Yu. L. Gurevich, IOP Conf. Series Earth and Environmental Science, 421 (2020)

9. V. Yu. Stupko, N. V. Zobova., Yu. L. Gurevich, Agricultural scientific journal, 11 (2020)

10. M. T. Tarasenko, Green cuttings of garden and forest crops (Moscow, Publishing house of the Moscow Agricultural Academy, 1991) 